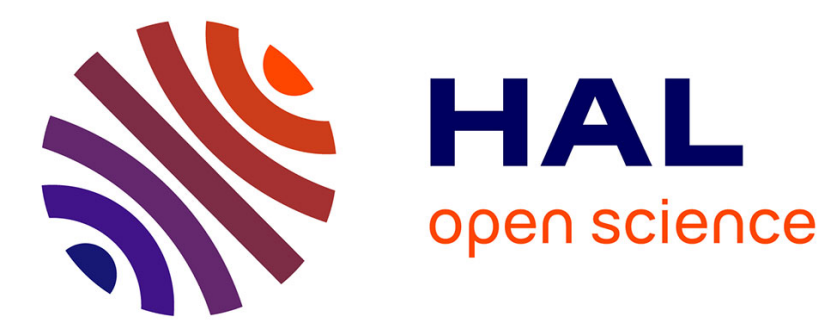

\title{
Passive Fault Tolerant Control of PEMFC air feeding system
}

\author{
Carole Lebreton, Cédric Damour, Michel Benne, Brigitte Grondin-Perez, \\ Jean-Pierre Chabriat
}

\section{- To cite this version:}

Carole Lebreton, Cédric Damour, Michel Benne, Brigitte Grondin-Perez, Jean-Pierre Chabriat. Passive Fault Tolerant Control of PEMFC air feeding system. International Journal of Hydrogen Energy, 2016, 41, pp.15615 - 15621. 10.1016/j.ijhydene.2016.06.210 . hal-01388039

\section{HAL Id: hal-01388039 \\ https://hal.univ-reunion.fr/hal-01388039}

Submitted on 26 Oct 2016

HAL is a multi-disciplinary open access archive for the deposit and dissemination of scientific research documents, whether they are published or not. The documents may come from teaching and research institutions in France or abroad, or from public or private research centers.
L'archive ouverte pluridisciplinaire HAL, est destinée au dépôt et à la diffusion de documents scientifiques de niveau recherche, publiés ou non, émanant des établissements d'enseignement et de recherche français ou étrangers, des laboratoires publics ou privés. 


\title{
Short Communication
}

\section{Passive Fault Tolerant Control of PEMFC air feeding system}

\author{
Carole Lebreton ***, Cédric Damour, Michel Benne*, Brigitte Grondin-Perez, \\ Jean-Pierre Chabriat
}

$L E^{2}$ P, EA 4079, University of La Reunion, 15 Av. Rene Cassin, BP 7151, 97715 Saint-Denis, France

\begin{abstract}
A B S T R A C T
In this paper, a Passive Fault Tolerant Control strategy dedicated to air feeding system fault based on an auto-tuning PID regulator is designed and implemented on a real fuel cell test bench. The present work compares the auto-tuning PID strategy performance to classical PID controller and highlights its benefits during faulty operation. Experimental results demonstrate the effectiveness of the proposed approach to regulate oxygen stoichiometry in real-time operation while maintaining a proper system performance under faulty situations. Unlike the classical PID controller, the proposed Passive Fault Tolerant Control System shows highly satisfactory performance in terms of setpoint tracking accuracy and disturbances rejection capability during faulty operations.
\end{abstract}

\section{Introduction}

Through its various possible applications, PEMFC (Polymer Electrolyte Membrane Fuel Cell) is one of the most popular fuel cell technologies. PEMFCs are used worldwide in stationary, transport and portable units, thanks to high power density and low operating temperature (around $80^{\circ} \mathrm{C}$ ). In 2013, PEMFCs generated $68 \mathrm{MW}$ over 215.3 MW of global produced energy by all types of FC [1] and PEMFC number of shipments increases year by year. PEMFC research and development are still encouraged and supported by industries as FCEV (Fuel Cell Electrical Vehicle) production which has evolved for few years from concept cars to series-produced cars. However, in order to enhance large-scale commercialization, the FC lifetime and FC system reliability have still to be improved.

FC lifetime highly depends on internal degradations, which are classified into two types: ageing degradations and catastrophic degradations. Ageing degradations are long term degradations, as catalyst layer thinning, membrane conductivity losses and bipolar plates corrosion. Catastrophic degradations are membrane pinholes formations, membrane cracking, membrane and catalyst poisoning. Although FC ageing degradations are unavoidable, they can be accentuated by improper operating conditions [2]. Among inadequate operating conditions consequences, gas starvation is recognized as one of the most important factor that increases FC degradations and therefore reduces drastically FC lifetime.

\footnotetext{
* Corresponding author.

** Corresponding author.

E-mail addresses: carole.lebreton@univ-reunion.fr (C. Lebreton), michel.benne@univ-reunion.fr (M. Benne).
} 


$$
\begin{aligned}
& \text { Nomenclature } \\
& \text { Abbreviations } \\
& \dot{m}_{\text {air }} \quad \text { Air mass flow rate, } \mathrm{sccm} \\
& \mathrm{S}_{\mathrm{O}_{2}} \quad \text { Oxygen excess ratio, - } \\
& \mathrm{V} \quad \text { Cell voltage, } \mathrm{V}
\end{aligned}
$$

\section{Exponents}

$\begin{array}{ll}\text { lin } & \text { Linearised expression } \\ \text { exp } & \text { Experimental value } \\ \text { set } & \text { Setpoint value }\end{array}$

Subscripts

autoT Related to auto-tuning PID control strategy

class Related to classical PID control strategy

Gas starvation can be induced by an actuator malfunction in the air feeding system as defective or miscalibrated air mass flow controllers or compressors, which involves incorrect application of the oxygen excess ratio setpoint. The capability of a system to maintain optimal operation in spite of malfunctions is defined in the industry as the concept of resilience [1]. Improving the FC system resilience to air feeding system malfunctions is an important requirement to enhance its reliability. This goal can be achieved thanks to Fault Tolerant Control Strategies (FTCS) development.

Fault Tolerant Control is a highly developed topic in safetycritical applications such as transports, aircrafts, spacecrafts and nuclear power plants [3]. A FTCS is able to automatically manage faults or malfunctions occurrence, while ensuring an optimal or suboptimal operation. FTCS are classified into two main types: Active and Passive FTCS (respectively called AFTCS and PFTCS). The AFTCS is characterized by an adaptation, a reconfiguration of the initial control strategy during faulty operation. Three sub-categories of AFTCS can be defined, according to the used fault management strategy: by a controller reconfiguration, a controller selection, or using hiding-fault paradigm.

The first method includes a Fault Detection and Isolation (FDI) block and a reconfiguration module. The FDI block communicates the State-Of-Health (SOH) of the system to the reconfiguration module which undertakes the appropriate controller reconfiguration. This reconfiguration may be a change in the setpoint value, in the controller inputs, or in the controller constraints. The controller selection method, however, does not contain FDI method. After operating point and performance evaluation thanks to system inputs/outputs observation, a decision-making module selects in a predefined bank the most appropriate controller to ensure optimal performance. The selection of this controller can be computed thanks to Unfalsified Control (UC). The third method to achieve AFTCS is the hiding-fault paradigm. An additional module defined according to the fault (also called reconfiguration block) is inserted between the controller and the plant. From the controller standpoint, the whole reconfiguration block and faulty plant constitutes a healthy plant, with an appropriate behaviour for a proper regulation. Therefore, the controller does not require retuning.

Conversely to AFTCS, PFTCS does not include reconfiguration mechanisms or FDI. PFTCS, as it name indicates, remains passive to fault occurring: the fault is not detected and no reconfiguration is undertaken. The fault tolerance of PFTCS is provided during the controller synthesis step: expected faults are listed and taken in account in order to build a control strategy insensitive to these faults. Most often, the intrinsic robustness of usual control strategies as Model Predictive Controller (MPC) is used to reach fault tolerance.

FTCS applied to fuel cells is at an early stage of development. Indeed, even if a wide variety of control strategies and diagnosis approaches have been reported in literature, a very few publications deal specifically with FTCS.

Moreover, most of works dealing with FTCS are dedicated to FCEV applications. Quan et al. [4] present an AFTCS dealing with sensors faults. A FDI tool based on residual computation is used. The redundancy is implemented thanks to Artificial Neural Network (ANN) models describing each system sensor behaviour. In case of fault, a reconfiguration of the inputs of the inner controller is undertaken: the values delivered by the failed sensors are replaced by the output of the sensors ANN models. This strategy is tested in simulation for a $60 \mathrm{~kW}$ automotive FC system, and the results show the efficiently of the FDI and system fault tolerant enhancement.

Xu et al. [5] propose an AFTCS dedicated to a city bus hybrid powertrain power management, in order to appropriately divide the power demand between the FC stack and the Li-ion battery. Different faults as accelerating pedal faults, temperature management faults and battery $\mathrm{SOH}$ estimation faults are detected thanks to a FDI tool based on analytical and physical redundancies. In case of fault, a remedial action is selected by a decision-making module, in order to recover desired performance. Experimental results show the effectiveness of this strategy.

Aouzellag et al. [6] present an AFTCS dedicated to a hybrid FCEV included ultra-capacitors in order to reduce the related degradations of these components and to increase their lifetime. The fault detection consists of state estimation for the five phases of the two Permanent Magnetic Synchronous Machines (PMSM). In case of open phases, the reconfiguration module selects a new set of current values to supply the PMSM.

Guilbert et al. proposed an AFTCS applied to a 3-legs Interleaved DC/DC Boost Converter (IBC) to prevent ageing degradation due to current ripple. A FDI module detects the faulty leg, and according to this diagnosis, the PWM (Pulse Width Modulation) gate control signal is adjusted avoiding undesired current ripple. An experimental test shows good performance of this strategy. In another work, Guilbert et al. [7] investigate the effects of the same fault in a 4-legs Floating 
IBC (FIBC), and propose remedial actions to reduce its effects thanks to the previously proposed AFTCS.

Other works focus on AFTCS applied to FC systems in order to provide an appropriate control of two important parts of the system: water management and air feeding system. Lebreton et al. [8] present an AFTCS containing a FDI based on analytical redundancy, a reconfiguration module and an auto-tuning PID regulator. In case of water management faults (flooding or drying out), the reconfiguration module designs the appropriate oxygen excess ratio value as inner controller setpoint. The proposed AFTCS is experimentally tested on a $50 \mathrm{~cm}^{2}$ PEMFC, and experimental results show that the proposed strategy improves the system performance and reliability. Ari et al. [9] use AFTCS to achieve FTC of air feeding system. Tested in simulation thanks to a FC system model inspired of Pukrushpan work [10] and implemented using MatLab/Simulink ${ }^{\circledR}$, the strategy performance is assessed face to parametric, dynamic and sensors faults. The appropriate controller is selected in a bank of three controllers thanks to UC and according to the evaluation of the system performance result. Puig et al. [11] present an AFTCS containing a MPC in order to avoid air starvation during compressor malfunctions. A FDI tool evaluates the new operating-range of the air compressor and this new value is included to the predictive model as new constraints. The authors compare PFTCS and AFTCS performances, and the simulated results show the superiority of the AFTCS. Rotondo et al. [12] present a fault-hiding paradigm to achieve fault tolerance against controller compressor faults. In actuator fault case, the reconfiguration block is called Virtual Actuator and allows a proper regulation of oxygen excess ratio. The strategy is tested in simulation and allows to improve the system performance.

To our best knowledge, this work is a first attempt to apply an on-line PFTCS to PEMFC air feeding system faults.

In this paper, the performance of a PFTCS against air feeding system faults based on a self-tuning PID controller tolerant to actuator faults is assessed. Through the integration of the modelling error in the manipulated variable computation, the PID controller compensates the fault and ensures to promptly reach the setpoint. This paper is organised as follows: Section Experimental description is dedicated to the experimental description. The Section Auto-tuning PID strategy presents the PFTCS based on auto-tuning PID strategy. Finally, Section Experimental results deals with the online experimental results of the FTCS in terms of tracking capability and disturbances rejection ability.

\section{Experimental description}

The test bench used to evaluate the PFTCS performance is manufactured by Fuel Cell Technologies, Inc. The MEA of the tested Fuel Cell is a five layers single cell of $50 \mathrm{~cm}^{2}$, made of Nafion N115 and produced by Paxitech ${ }^{\circledR}$. Anode and cathode are respectively supplied with pure hydrogen and air and gas circulation is assumed by quadruple serpentine bipolar plates.

The System Control and Data Acquisition (SCDA) is implemented using LabView ${ }^{\mathbb{R}}$ and ensures the application of the desired operating conditions. The setpoint values of temperatures, pressures and air flow rates are sent to auxiliaries such as heating cooling subsystem, pressure and mass flow controllers. Air supply system consists of mass flow rate controllers fed by a pressurised air bottle. The test bench air feeding controllers are elastomer-sealed mass flow controllers (1179A Mass-Flo ${ }^{\circledR}$ General Purpose Mass Flow Controller), built by MKS Instruments, which measure and control the air mass flow rate.

In order to test an external control strategy, a communication protocol between the SCDA and MatLab ${ }^{\circledR}$ is set up. The PFTCS is computed with MatLab ${ }^{\circledR}$ and the manipulated variable value is sent to the SCDA, which sends the information to the MKS components. The communications between Mat$\mathrm{Lab}^{\circledR}$, the SCDA and the MKS ${ }^{\circledR}$ components are synchronised, and the sample time $\Delta t$ is set to $4 \mathrm{~s}$ for technical and experimental constraints.

\section{Fault simulation}

The selected fault is an air feeding system malfunction. The air mass flow controller component fault is experimentally simulated. Actuator fault is easy to simulate, thanks to an offset induced artificially between the value calculated by the control strategy and the value actually sent to the actuator. This offset is applied after the computation of the manipulated variable, before its communication to the SCDA. Actually, an incorrect setpoint is intentionally applied to the $\mathrm{MKS}^{\circledR}$ controller.

\section{Auto-tuning PID strategy}

The auto-tuning PID strategy is based on the work of Chen et al. [13]. This strategy consists of an adaptative PID controller suitable for nonlinear systems, and uses an Artificial Neural Network as internal model predictor. At each sample time, the internal model is linearized. An optimization algorithm based on the linearized ANN and a General Minimum Variance law allows to estimate the most suitable PID parameters, that subsequently replace the previous values.

Already applied to sugar crystallization process by Beyou et al. [14], this strategy was then studied for oxygen excess ratio regulation on a FC system by Damour et al. [15]. A complete description of the control strategy can be found in these works.

Fig. 1 depicts the auto-tuning PID strategy scheme and the interactions with the faulty actuator.

Two important blocks can be noticed, the Artificial Neural Network (ANN) model and the General Minimum Variance Control (GMV) law. The ANN is used as internal model predictor to compute a one-step-ahead prediction of the controller output. The model predicts the oxygen excess ratio thanks to air mass flow rate and load current values. The GMV control law extracts the optimum values of PID coefficients from an instantaneous linearisation of the ANN model. In this work, in order to achieve fault tolerance, the initial control algorithm implemented by Chen et al. has been modified as follows: the ANN modelling error is taken in account inside the GMV block, during the estimation of the PID parameters. In the case of a faulty actuator, the air mass flow rate calculated by the control strategy is misapplied which induces that 


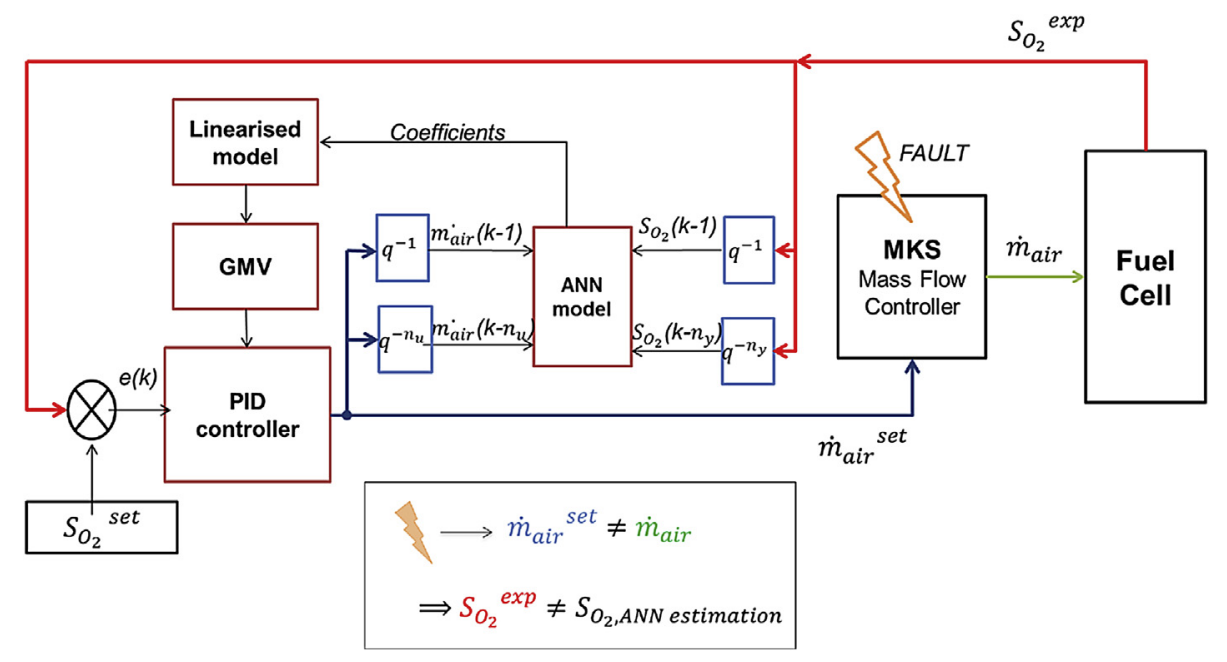

Fig. 1 - Auto-tuning PID strategy.

the oxygen excess ratio setpoint is not reached. In fact, this fault is interpreted by the proposed strategy as a modelling error, and PID parameters are updated accordingly, that allows to reach the setpoint in spite of the actuator malfunction.

In the present study, the manipulated variable $u$ is defined as the air mass flow rate $\dot{m}_{\text {air }}$ and the controlled variable $y$ is set as the oxygen excess ratio $\mathrm{S}_{\mathrm{O}_{2}}$.

The computation of the new value of the manipulated variable $u$ is performed thanks to the classical PID equation:

$u(k)=u(k-1)+\Delta u(k)$

The velocity form is depicted as follows:

$\Delta u(k)=\mathbf{e}^{T} \cdot \mathbf{k}(k)$

with

$\mathbf{e}=\left[\begin{array}{lll}e(k) & e(k-1) & e(k-2)\end{array}\right]^{\mathrm{T}}$

and

$\mathbf{k}(k)=\left[k_{0} k_{1} k_{2}\right]$

where $e(k)=y^{\text {set }}(k)-y(k)$ is the trajectory tracking error and $k_{0}$, $k_{1}$ and $k_{2}$ are parameters which contain the PID parameters $k_{c}$, $\tau_{i}$ and $\tau_{d}$ :

$k_{0}=k_{c}\left(1+\frac{\Delta t}{2 \tau_{i}}+\frac{\tau_{d}}{\Delta t}\right)$

$k_{1}=-k_{c}\left(1-\frac{\Delta t}{2 \tau_{i}}+\frac{2 \tau_{d}}{\Delta t}\right)$

and

$k_{2}=\frac{k_{c} \tau_{d}}{\Delta t}$

To compute the most suitable PID parameters, the following goal function is used:

$\min J=\frac{1}{2} \min _{k_{c}, \tau_{i}, \tau_{d}}\left[e^{2}(k+1)+\mu \Delta u^{2}(k)\right]$

where $\mu$ is the weighting penalty parameter. The value of $e$ $(k+1)$ is not available, because $y(k+1)$ is not available either at present time. The ANN model output linearisation using first Taylor development provides an expression of $\widehat{y}^{\text {lin }}(k+1)$, used as an approximation of $y(k+1)$, and developed as follows:

$\widehat{y}^{\operatorname{lin}}(k+1) \simeq$ bias $-\sum_{i=1}^{n_{y}} a_{i} y(k-i)+\sum_{i=1}^{n_{u}} b_{i} u(k-i)$

where $a_{i}$ and $b_{i}$ are the linear model coefficients of the output and the inputs.

Let define $\hat{e}^{\text {lin }}(k+1)$ as:

$$
\begin{aligned}
\hat{e}^{\operatorname{lin}}(k+1)= & y^{\text {set }}(k+1)-\sum_{i=1}^{n_{y}} a_{i} y(k-i)-\sum_{i=1}^{n_{u}} b_{i} u(k-i)-\text { bias } \\
& -e^{\text {model }}
\end{aligned}
$$

where $e^{\text {model }}$ is the modelling error at present time, $n_{y}$ and $n_{u}$ the number of needed past inputs and outputs.

A new goal function is defined:

$\min J \approx \min _{k_{c}, \tau_{i}, \tau_{d}} L=\frac{1}{2} \min _{k_{c}, \tau_{i}, \tau_{d}}\left[\hat{e}^{\operatorname{lin}^{2}}(k+1)+\mu \Delta u^{2}(k)\right]$

The minimisation of this criterion allows to define the most appropriate PID parameters, taking in account the fault as modelling error.

\section{Experimental results}

\section{PFTCS results}

The auto-tuning PID controller performance during no-fault operations has already been investigated in a previous work. It has been demonstrated that this controller shows high accuracy in setpoint tracking and good disturbances rejection capability [15]. In the present work, the tolerance and the flexibility of this controller to actuator faults are put to test.

The auto-tuning PID controller is tested on the real PEM fuel cell system, through two different experimental scenarios: evaluation of the controller tracking capability and 
evaluation of performance in term of disturbances rejection. These two scenarios are performed under normal and faulty operations. During faulty operations, an offset with a value of $-200 \mathrm{sccm}$ is applied to input air flow rate.

\section{Scenario 1: tracking capability}

Fig. 2 depicts the tracking capability test. During this test, the fault appears between $t=240 \mathrm{~s}$ and $t=440 \mathrm{~s}$ and the load current is set to $15 \mathrm{~A}$.

Thanks to the use of the future setpoint value $S^{\text {set }}(k+1)$ to compute the manipulated variable, the auto-tuning PID controller is able to promptly track the desired value. Conversely, the classical PID response is delayed by a sampling time. Except that delay, during no-fault operation the both strategies performance is similar. At fault occurrence, the classical PID cannot regulate the oxygen excess ratio as expected, and the experimental value of the oxygen excess ratio $S_{\text {class }}^{\exp }$ doesn't reach the desired value. Auto-tuning PID demonstrates reactivity and efficiency when fault occurs: $S_{\text {autoT }}^{\text {exp }}$ deviates briefly from Ref. $S^{\text {set }}$ and reaches the desired value back after one sampling time. During faulty operation the average value of Relative Error (RE) associated to classical PID controller is $21.43 \%$, whereas the value associated to autotuning PID strategy is $1.33 \%$. The RE are calculated thanks to the Equation (12). Fig. 3 highlights the superiority of the autotuning PID compared to the classical approach showing the RE associated to both strategies. The maximum value of relative error related to classical strategy reaches $113.26 \%$ during faulty operation, while the auto-tuning PID allows to remain below $17 \%$. Average and maximum values of $\mathrm{RE}$ are listed in Table 1.

$R E=\frac{\left|S^{\text {set }}-S^{\exp }\right|}{S^{\text {set }}}$

Scenario 2: disturbances rejection ability

The fault occurs between $t=280 \mathrm{~s}$ and $t=524 \mathrm{~s}$. Different load current steps are applied to the fuel cell while $S^{\text {set }}$ is fixed at 5 during all the experiments. Fig. 4 exhibits the experimental
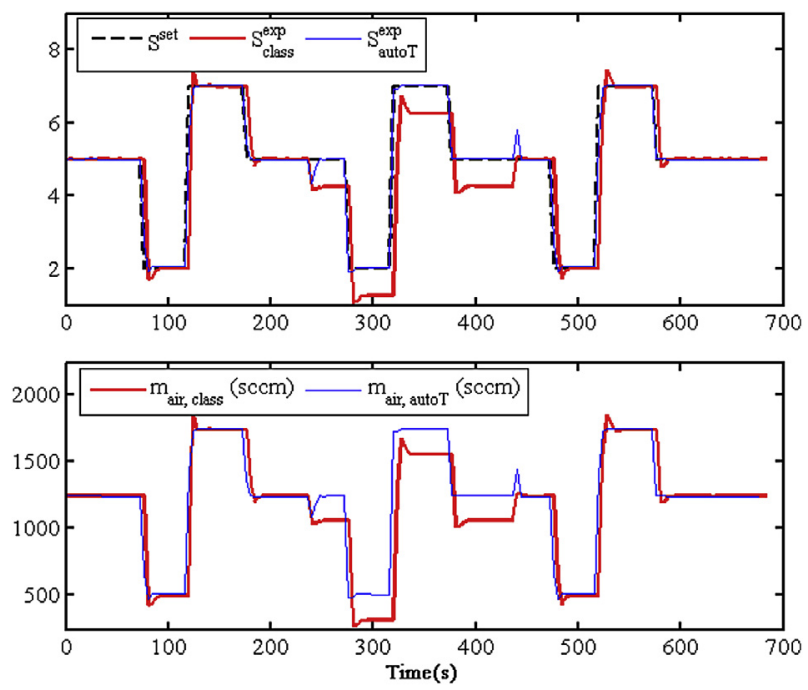

Fig. 2 - Tracking capability.

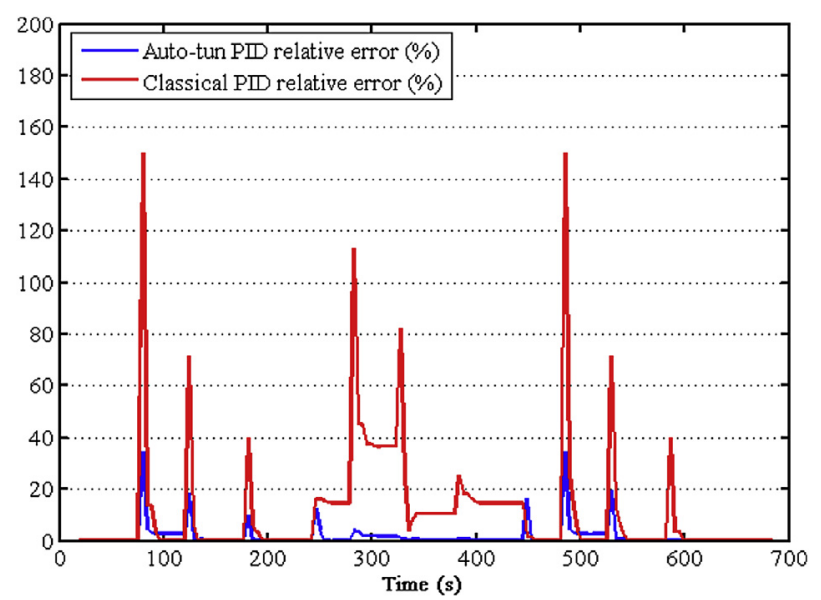

Fig. 3 - Control strategies relative errors during scenario 1.

\section{Table 1 - Control strategies relative errors during} scenario 1.

\begin{tabular}{|c|c|c|c|c|}
\hline & \multicolumn{2}{|c|}{ Healthy cond. } & \multicolumn{2}{|c|}{ Faulty cond. } \\
\hline & $\begin{array}{c}\text { Max RE } \\
(\%)\end{array}$ & $\begin{array}{c}\text { Mean RE } \\
(\%)\end{array}$ & $\begin{array}{c}\operatorname{Max} R E \\
(\%)\end{array}$ & $\begin{array}{c}\text { Mean RE } \\
(\%)\end{array}$ \\
\hline Class. PID & 150.07 & 5.75 & 113.26 & 21.43 \\
\hline $\begin{array}{l}\text { Auto-tun. } \\
\text { PID }\end{array}$ & 34.70 & 1.84 & 16.17 & 1.33 \\
\hline
\end{tabular}

results, and Fig. 5 shows the relative errors between $S^{\text {set }}$ and the experimental values $S_{\text {autoT }}^{\text {exp }}$ and $S_{\text {class }}^{\text {exp }}$.

During no-fault operation, $S_{\text {autoT }}^{\text {exp }}$ and $S_{\text {class }}^{\text {exp }}$ deviate briefly from Ref. $S^{\text {set }}$ at disturbance appearance (change of current step) and this deviation is more important during classical approach than during auto-tuning PID control strategy. At fault beginning, it can be noticed that auto-tuning PID provides an oxygen excess ratio value which deviates briefly from Ref. $S^{\text {set }}$ before reaching it again, while classical PID controller oxygen excess ratio remains far from Ref. $S^{\text {set }}$. The RE average
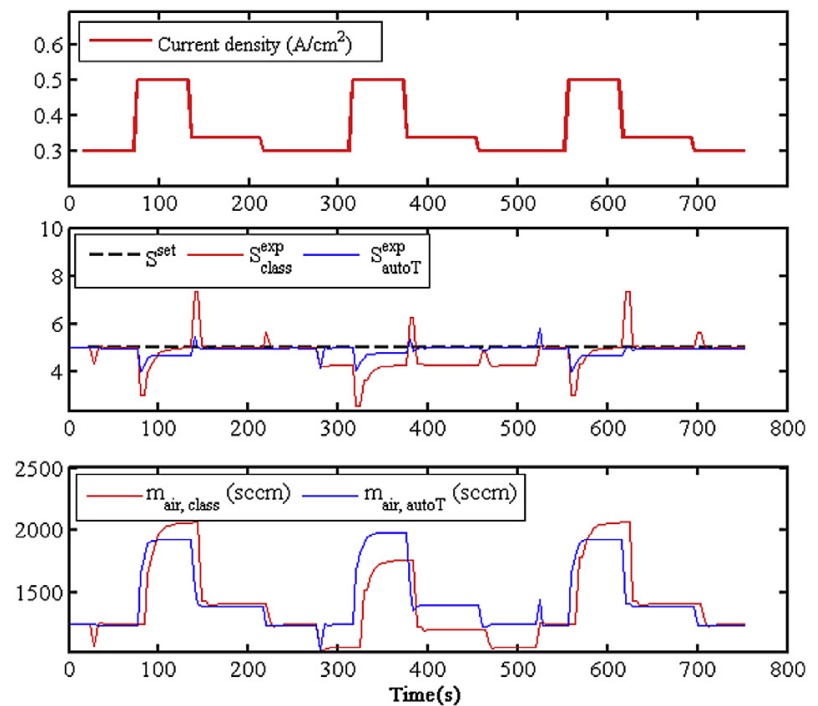

Fig. 4 - Disturbances rejection ability. 


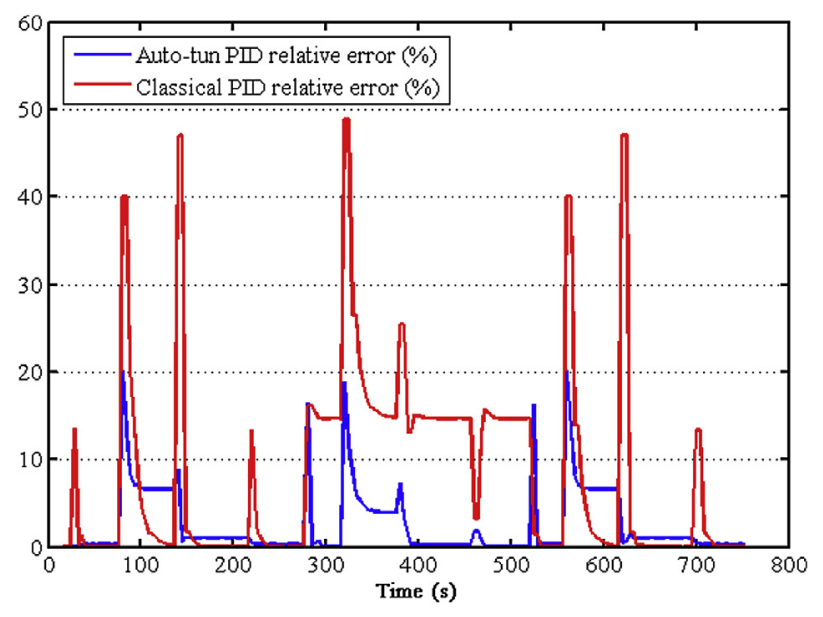

Fig. 5 - Control strategies relative errors during scenario 2.

value associated to $S_{\text {class }}^{\text {exp }}$ during faulty operation is about $13.71 \%$ (whereas the RE average value of the proposed strategy is about $1.35 \%$ ). The difference between maximum relative errors values is noticeable: $48.85 \%$ for classical approach and $18.89 \%$ related to auto-tuning PID. The control strategies performance comparison can be seen in Table 2. The associated mass flow rate reduction is about $194.79 \mathrm{sccm}$ in comparison with the value resulting from the auto-tuning PID controller.

\section{Effect on FC performance}

Fig. 6 represents the voltage values evolution during the disturbances rejection tests and the associated relative error.

With the emergence of the fault at $t=280 \mathrm{~s}$, the voltage value associated to the classical PID controller reduces slightly while the auto-tuning PID controller induces a quite constant voltage value. It is a well-known fact that the $\mathrm{S}_{\mathrm{O}_{2}}$ value influences the FC performance, and in the present case, even if the observed voltage reduction is noticeable, its amplitude during the fault is not significant. Actually, the $R E_{v}$ average value during the fault between the two voltage values is about $0.61 \%$ with a maximum gap of $7.8 \%$ at $t=320$ s. It can be explained as follows: despite the fact that the classical PID controller does not allow to reach the setpoint $S^{\text {set }}=5$, the experimental value $S_{\text {class }}^{\text {exp }}$ during faulty operation is maintained at least at a value of 2.56 . This value remains a sufficient and adequate air mass flow rate to keep the FC in nominal operating conditions. In order to investigate the benefits of the proposed control strategy on voltage, other tests have to be conducted with lower $S^{\text {set }}$ values. The relative error $R E_{v}$ is calculated thanks to the following equation:

Table 2 - Control strategies relative errors during scenario 2.

\begin{tabular}{lccccc} 
& \multicolumn{2}{c}{ Healthy cond. } & & \multicolumn{2}{c}{ Faulty cond. } \\
\cline { 2 - 3 } \cline { 5 - 6 } & $\begin{array}{c}\text { Max RE } \\
(\%)\end{array}$ & $\begin{array}{c}\text { Mean RE } \\
(\%)\end{array}$ & & $\begin{array}{c}\text { Max RE } \\
(\%)\end{array}$ & $\begin{array}{c}\text { Mean RE } \\
(\%)\end{array}$ \\
\hline Class. PID & 40.07 & 0.73 & & 48.85 & 13.71 \\
Auto-tun. & 20.17 & 2.45 & & 18.89 & 1.35 \\
$\quad$ PID & & & & & \\
\hline
\end{tabular}
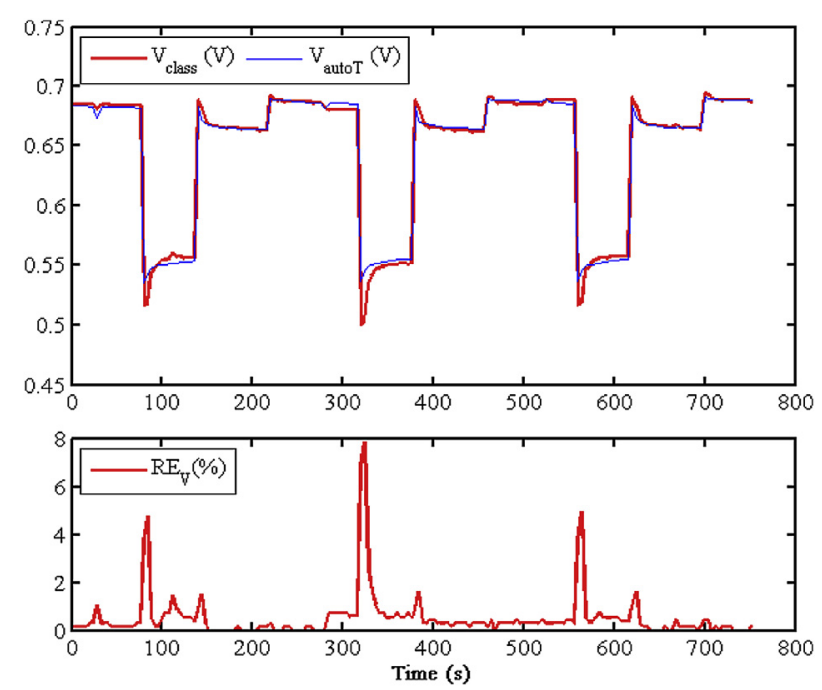

Fig. 6 - Effect of control strategy on voltage.

$R E_{v}=\frac{\left|\mathrm{V}_{\text {autoT }}-\mathrm{V}_{\text {class }}\right|}{\mathrm{V}_{\text {autoT }}}$

With $\mathrm{V}_{\text {auto }}$ and $\mathrm{V}_{\text {class }}$, the voltages resulting respectively from the auto-tuning PID controller and the classical PID controller tests.

\section{Conclusion and perspectives}

In this work, the performance of a Passive Fault Tolerant Control System based on an auto-tuning PID controller, and a classical PID controller have been experimentally compared on a real fuel cell system. The effectiveness and benefits of the proposed auto-tuning PID strategy during faulty operation have been highlighted through several experimental tests. The auto-tuning PID controller has shown good fault tolerance to actuator faults, avoiding improper gas feeding. The autotuning PID controller regulates the oxygen excess ratio and uses the air mass flow rate as manipulated variable. The proposed strategy has been designed to manage actuator faults as modelling errors, and to take these errors in account during manipulated variable computation.

The experimental results exhibit the superiority of the auto-tuning PID on the classical PID controller. In one iteration, the fault has been totally compensated and the setpoint has been reached thanks to the proposed strategy, whereas the classical PID controller has been inefficient during faulty conditions. The auto-tuning PID strategy has demonstrated good tracking capability and good disturbances rejection ability both in healthy and in faulty conditions. These results confirm that the presented auto-tuning PID can be used as PFTCS in case of actuator faults in order to ensure proper gas feeding. The significant reduction of air mass flow associated to a classical PID controller has been avoided, that allows to preserve FC from gas starvation and involved ageing degradations. Moreover, this strategy is easy to implement and does not require any additional equipment. 
Nevertheless, although the PFTCS strategy has proven to be tolerant to faults, it does not detect the fault. The detection and the isolation of the malfunction would allow an alarm setting to inform users that a servicing step is required. Further works are in progress to investigate the possibility to use the value of the modelling error as residue to detect and isolate the fault. In this aim, acceptance thresholds have to be defined or auto-adaptive thresholds have to be computed. Furthermore, even if the proposed strategy has demonstrated its tolerance to actuator faults, an analysis of its behaviour during other faults occurrence has to be conducted, as in case of water management faults.

R E F E R E N C E S

[1] E4tech, Hart D, Lehner F, Rose R, Lewis J. The fuel cell industry review. Tech Rep 2014.

[2] Pei P, Chen H. Main factors affecting the lifetime of proton exchange membrane fuel cells in vehicle applications: a review. Appl Energy 2014;125:60-75.

[3] Zhang Y, Jiang J. Bibliographical review on reconfigurable fault-tolerant control systems. Annu Rev Control 2008;32(2):229-52.

[4] Quan R, Quan S, Huang L, Xie C. Fault diagnosis and faulttolerant control for multi-sensor of fuel cell system using two-level neural networks. J Comput Inf Syst 2010;11:3703-11.

[5] Xu L, Li J, Ouyang M, Hua J, Li X. Active fault tolerance control system of fuel cell hybrid city bus. Int J Hydrogen Energy 2010;35(22):12510-20.

[6] Aouzellag H, Ghedamsi K, Aouzellag D. Energy management and fault tolerant control strategies for fuel cell/ultra- capacitor hybrid electric vehicles to enhance autonomy, efficiency and life time of the fuel cell system. Int J Hydrogen Energy 2015;40(22):7204-13.

[7] Guilbert D, Gaillard A, N'Diaye A, Djerdir A. Power switch failures tolerance and remedial strategies of a 4-leg floating interleaved DC/DC boost converter for photovoltaic/fuel cell applications. Renew Energy 2016;90:14-27.

[8] Lebreton C, Benne M, Damour C, Yousfi-Steiner N, GrondinPerez B, Hissel D, et al. Fault tolerant control strategy applied to PEMFC water management. Int J Hydrogen Energy 2015;40(33):10636-46.

[9] Ari I, Ricardo, S.S.P. Using the unfalsified control concept to achieve fault tolerance. In: Myung C, editor. 17th World congress the International federation of automatic control; 2008. p. 1236-42.

[10] Pukrushpan JT. Modeling and control of fuel cell systems and fuel processors. Ph.D. thesis. University of Michigan; 2003.

[11] Puig V, Feroldi D, Serra M. Fault-tolerant MPC control of PEM fuel cells. In: 17th world congress IFAC; 2008. p. 11112-7. ISBN 9781123478.

[12] Rotondo D, Puig V, Nejjari F. Fault tolerant control of a PEM fuel cell using qLPV virtual actuators. IFAC-Papers OnLine 2015;48(21):271-6.

[13] Chen J, Huang TC. Applying neural networks to on-line updated PID controllers for nonlinear process control. J Process Control 2004;14(2):211-30.

[14] Beyou S, Grondin-Perez B, Benne M, Damour C, Chabriat JP. Control improvement of a C sugar cane crystallization using an auto-tuning PID controller based on linearization of a neural network, World Academy of Science, Engineering and Technology. Int J of Comput Electr Autom Control Inf Eng 2009;3(6):1646-51.

[15] Damour C, Benne M, Lebreton C, Deseure J, Grondin-Perez B. Real-time implementation of a neural model-based selftuning PID strategy for oxygen stoichiometry control in PEM fuel cell. Int J Hydrogen Energy 2014;39(24):12819-25. 